\title{
Capturing Changes in the Brain Microenvironment during Initial Steps of Breast Cancer Brain Metastasis
}

\author{
Mihaela Lorger and Brunhilde Felding-Habermann \\ From the Department of Molecular and Experimental Medicine, \\ The Scripps Research Institute, La Jolla, California
}

Brain metastases are difficult to treat and mostly develop late during progressive metastatic disease. $\mathrm{Pa}$ tients at risk would benefit from the development of prevention and improved treatments. This requires knowledge of the initial events that lead to brain metastasis. The present study reveals cellular events during the initiation of brain metastasis by breast cancer cells and documents the earliest host responses to incoming cancer cells after carotid artery injection in immunodeficient and immunocompetent mouse models. Our findings capture and characterize heterogeneous astrocytic and microglial reactions to the arrest and extravasation of cancer cells in the brain, showing immediate and drastic changes in the brain microenvironment on arrival of individual cancer cells. We identified reactive astrocytes as the most active host cell population that immediately localizes to individual invading tumor cells and continuously associates with growing metastatic lesions. Upregulation of matrix metalloproteinase-9 associated with astrocyte activation in the immediate vicinity of extravasating cancer cells might support their progression. Early involvement of different host cell types indicates environmental clues that might codetermine whether a single cancer cell progresses to macrometastasis or remains dormant. Thus, information on the initial interplay between brain homing tumor cells and reactive host cells may help develop strategies for prevention and treatment of symptomatic breast cancer brain metastases. (Am J Pathol 2010, 176:2958-2971; DOI: 10.2353/ajpath.2010.090838)

Brain metastases are diagnosed in 10 to $40 \%$ of all cancer patients, and the incidence is rising as patients live longer due to improved treatments for extracranial metastases. ${ }^{1,2}$ Brain lesions are most frequently associated with lung cancer, breast cancer, and melanoma. ${ }^{1,2}$ Unfortunately, brain metastases are still very difficult to treat and the mechanisms underlying their establishment and progression are poorly understood. Thus, information in this direction and models for analysis are a prerequisite for the development of new, efficient therapies.

The essential role of the tumor microenvironment in cancer progression has been well documented for extracranial malignancies, and recent findings indicate that the tumor microenvironment might be a suitable target in anticancer therapies, as well as a valuable biomarker for prognostic purposes. ${ }^{3-5}$ The brain provides a unique environment with paracrine growth factors that differ from most other organs. ${ }^{6,7}$ The involvement of brain-resident cells including brain endothelial cells, microglia, and astrocytes in the pathology of primary and metastatic brain tumors is only partially understood. Brain endothelial cells are the first host cell type that circulating cancer cells encounter when they arrest within the brain microvasculature. In addition to posing the initial barrier for brain invasion, endothelial cells and their basement membrane seem to play important roles in supporting the growth of brain metastases as well as brain tumor stem cells. ${ }^{8-10}$ So far, only a few studies documented cancer cell arrest and extravasation in the brain in vivo ${ }^{11-13}$. Once incoming cancer cells begin to infiltrate the brain tissue, they encounter a number of host cell types that may respond to their arrival. Microglia constitute the tissue macrophages of the central nervous system and are the main respond-

Supported by postdoctoral fellowship from the Susan G. Komen Breast Cancer Foundation (PDF0707935; to M.L.), National Institutes of Health grants CA095458 and CA112287 (to B.F.-H.), California Breast Cancer Research Program grants 12 NB0176 and 13 NB0180 (to B.F.-H.), and Department of Defense grant W81XWH-08-1-0468 (to B.F.-H.).

Accepted for publication January 26, 2010

Supplemental material for this article can be found on http://ajp. amjpathol.org

Address reprint requests to Brunhilde Felding-Habermann, Ph.D., or Mihaela Lorger, Ph.D., Department of Molecular and Experimental Medicine, The Scripps Research Institute, 10550 North Torrey Pines Road, MEM-150, La Jolla, CA 92037. E-mail: brunie@scripps.edu or mlorger@ scripps.edu. 
ers to primary brain tumors. Activated microglia can be frequently found in the vicinity of brain lesions, ${ }^{14-18}$ and the inhibition of microglial activation has been shown to significantly reduce glioma proliferation. ${ }^{14}$ Microglia secrete multiple cytokines, growth factors, and enzymes that can directly or indirectly lead to immunosuppression, angiogenesis, tumor proliferation, and invasion. ${ }^{15,17,19,20}$ In contrast to these cancer promoting effects, however, microglia has also been reported to elicit cytotoxicity toward lung cancer brain metastases. ${ }^{21}$ Thus, microglial cells seem to play diverse roles in cancer progression, which might be related to their heterogeneity and distinct stages of activation. In addition to microglia, reactive astrocytes have been frequently observed in the vicinity of primary and metastatic brain tumors in animal models as well as in human patients. ${ }^{6,15,22}$ Astrocytes were shown to support brain tumor growth by secretion of cytokines, heparanase, and neurotrophic factors such as transforming growth factor- $\alpha$, Stromal cell-derived factor 1 (SDF-1) Sphingosin-1 phosphate, and Glial cell line-derived neurotrophic factor. ${ }^{17,23-25}$ Furthermore, an immortalized astrocyte cell line has been recently shown to promote cell division and survival in lung adenocarcinoma cells in vitro. ${ }^{26}$

Although the microenvironment of established brain tumors has been intensively studied, the induction of changes in the brain during the initial steps of cancer cell invasion from the bloodstream has not been described previously. This is probably due to challenges in the establishment of specialized animal models and techniques that allow efficient and detailed analysis of these early time points. However, an understanding of early events in particular is essential for the development of preventive therapies, which are urgently needed. Breast cancer brain metastases are thought to develop at a late stage of progressive metastatic disease and ultimately fail to respond to treatment. Therefore, effective therapies for prevention could be lifesaving for patients who are at risk for developing brain lesions.

In the present study, we analyzed the brain microenvironment during the initiation of hematogenous breast cancer brain metastasis, using animal models that allowed us to capture the involvement of different brainresident cells in this process. We found that cancer cells extravasated exclusively from capillaries. In some cell lines, this step preceded their proliferation and establishment of metastatic foci, whereas other cell lines began to proliferate within the brain microvasculature. However, the timing between tumor cell arrest and extravasation was always the same and required several days. Thus, survival of arrested cancer cells within brain capillaries might be a rate-limiting step in metastatic progression. This might be true specifically for the brain, because cancer cell penetration of the vessel wall in the brain is much slower than in other organs. ${ }^{13,27}$ Strikingly, arrest of individual tumor cells in brain capillaries induced diverse astrocytic and microglial responses, even before the tumor cells extravasated. These responses resulted in heterogeneous local changes of the initial tumor microenvironment. We speculate that these changes might influence the fate of individual cancer cells, promoting or restricting their progression into macrometastases. In the future, our models should enable detailed in vivo analyses of these early interactions and contribute to the development of preventive therapeutic approaches that target early host responses within the brain microenvironment. Such strategies may hold particular promise because cancer cells may constantly change their phenotype due to genetic instability, in contrast to the more stable host microenvironment. Thus, microenvironment-based therapies might find broader application for different cancer types and affect different stages of progression.

\section{Materials and Methods}

\section{In Vivo Mouse Models, Bioluminescence Imaging, and Tissue Preparation}

MDA-MB-435, MDA-MB-231, MDA-MB-231/brain, ${ }^{28} 4 \mathrm{~T} 1$, and MCF-7 cells were grown in Eagle's minimum essential medium supplemented with nonessential amino acids, vitamin mix, L-glutamin, pyruvate, and $10 \%$ serum. 4T1 cells were stably transduced with lentiviral green fluorescent protein (GFP)-expressing vector to enable their detection by immunofluorescence. For in vivo imaging, all tumor cell lines were stably transduced with Firefly luciferase (F-luc) in a lentiviral construct. ${ }^{29}$ F-luc-tagged cancer cells $\left(10^{4}, 2 \times 10^{4}\right.$, and/or $\left.10^{5}\right)$ were injected into the left internal carotid artery of female BALB/c mice (4T1 cells) or CB17/SCID mice (all other cell lines) in Eagle's minimum essential medium without supplements in a total volume of $50 \mu \mathrm{l}$. For surgery, mice were anesthesized with isofluorane. To detect hypoxia, Hypoxyprobe (Natural Pharmaceuticals Inc., Burlington, MA) (150 $\mu$ l of 10 $\mathrm{mg} / \mathrm{ml}$ i.p.) was injected into the animals 45 minutes before tissue harvest. The surgery protocol and all animal work were approved by the institutional animal care and use committee (American Association for the Accreditation of Laboratory Animal Care accredited).

Tumor cell arrest and growth within the brain tissue were monitored by repeated noninvasive bioluminescence imaging using an IVIS 200 system (Xenogen, Alameda, CA) after luciferin injection (i.p.). On day 1, 2, 3, $5,7,10$, and 50 to 70 posttumor cell injection, brain tissue was harvested after perfusing deeply anesthesized animals with $20 \mathrm{ml}$ of $0.9 \% \mathrm{NaCl}$, followed by $20 \mathrm{ml}$ of $4 \%$ paraformaldehyde in PBS. Isolated brain tissue was postfixed in $4 \%$ paraformaldehyde for 4 to 8 hours at $4^{\circ} \mathrm{C}$, then incubated in $25 \%$ sucrose/0.1 M sodium phosphate buffer at $4^{\circ} \mathrm{C}$ overnight, and snap-frozen on dry ice. Brains were cut entirely into $30-\mu \mathrm{m}$ cryosections, collected in Walter's antifreeze (30\% (v/v) ethylenglycol, $30 \%$ (v/v) glycerol, and $0.5 \mathrm{M}$ phosphate buffer) and stored at $-20^{\circ} \mathrm{C}$

\section{Immunohistochemistry and Immunofluorescence}

Before staining, floating sections were washed three times in PBS, treated with $3 \% \mathrm{H}_{2} \mathrm{O}_{2} / 10 \%$ methanol in PBS for 15 minutes, blocked in $10 \%$ goat serum/0.3\% Triton $\mathrm{X}-100$ in PBS for 1 hour, and incubated with primary 
antibody (Ab) overnight, followed by incubation with secondary horseradish peroxidase-, alkaline phosphatase-, or biotin-conjugated Abs (Jackson ImmunoResearch Laboratories, West Grove, PA and Vector Laboratories, Burlingame, CA) for 2 hours. For double and triple staining, sections were incubated sequentially with one $A b$ at a time. Different horseradish peroxidase substrates (diaminobenzidine; BD Pharmingen or Vector-SG, Vector Laboratories) and alkaline phosphatase substrate (Vector-Red; Vector Laboratories) were used to visualize the antigens. Signal from biotinylated Abs was amplified using an avidin-biotin complex kit (Vector Laboratories). After transferring the sections onto glass slides, nuclei were stained with Contrast Green (Kirkegaard \& Perry Laboratories, Gaithersburg, MD), and the slides were washed with isopropanol and briefly incubated in SafeClear II (Fisher Scientific, Pittsburgh, PA) before mounting in Permount (Fisher Scientific).

For immunofluorescence, secondary Abs conjugated with Alexa 488, Alexa 549, allophycocyanin (APC) (Invitrogen, Carlsbad, CA), tetramethylrhodamine isothiocyanate, or fluorescein isothiocyanate (Jackson ImmunoResearch Laboratories) were used, nuclei visualized with 4',6'-diamidino-2-phenylindole, and the slides were mounted in Gel Mount (Biomeda, Foster City, CA).

Primary Abs used were anti-CD34 (Abcam, Cambridge, MA), anti-mouse-CD31 (BD Pharmingen), anti-human CD44 (monocloncal Ab (mAb) 29.7), ${ }^{30}$ anti-glial fibrillar acidic protein (GFAP) (Promega, Madison, WI), anti-mouse Nestin mAb 353 (Chemicon International, Temecula, CA), antimatrix metalloproteinase (MMP)-9 (Ab-7, Oncogene Research Products, San Diego, CA), anti-SDF-1 (Santa Cruz Biotechnology), anti-Ki-67 (BD Pharmingen), anti-smooth muscle actin (Sigma-Aldrich, St. Louis, MO), anti-F4/80 (Cederlane Laboratories, Hornby, Ontario, Canada), antiplatelet-derived growth factor receptor $\beta$ (eBioscience, San Diego, CA), anti-human vimentin (DakoCytomation, Fort Collins, CO), anti-GFP (Chemicon International), anti-mouse $\mathrm{GPIb}_{\alpha}$ (Emfret Analytics, Eibelstadt, Germany), anti-Hypoxyprobe (Natural Pharmaceuticals Inc., Burlington, MA), and anti-fibrin (murine hybridoma HB8545; American Type Culture Collection). BS-1 lectin was from Sigma-Aldrich. The TACS TdT kit (R\&D Systems, Minneapolis, MN) was used for terminal deoxynucleotidyl transferase-mediated dUTP nick-end labeling staining.

Images were acquired with a Zeiss Axio Imager M1m microscope equipped with a digital camera, using $\times 10$ or $\times 20$ air objectives. Digital images were analyzed using AxioVision 4.6 software (Zeiss, Oberkochen, Germany). Confocal images were acquired with an Olympus IX81 microscope equipped with UltraVIEW VoX Confocal Imaging System (PerkinEImer, Wellesley, MA), using a $\times 40$ water immersion objective. Images were acquired and analyzed using the Velocity software.

\section{Quantification of Tumor Cell Extravasation}

To detect the tumor cells, tissues were stained with antiGFP Ab (4T1), anti-human CD44 (mAb 29.7), or human vimentin (human cell lines) and costained with anti-CD31 to visualize the vascular endothelium. The position of the tumor cells inside or outside blood vessels was determined for each detected tumor cell. For MDA-MB-435 cells, every fourth section throughout the entire brain was analyzed. At each time point (days 3,5 , and 7 ), $n=4$ brains were examined. On day 3, we found 253, 130, 90, or 301 tumor cells per brain, respectively, and 15, 16, 48, or 196 tumor cells on day 5. For MDA-MB-231/brain and $4 \mathrm{~T} 1$ cells, 60 randomly chosen events in each of two to three different animals were examined per time point. The percentage of intravascular versus extravascular tumor cells was calculated.

The gross quantification was performed using images acquired with Zeiss Axio Imager M1m microscope, which allowed for quantification of a large number of events. For a subset of events, the localization of cancer cells inside or outside the vasculature was confirmed by confocal microscopy.

\section{Quantification of Ki-67-Positive Cells}

Tissue was costained for Ki-67 and human CD44 (MDAMB-435) or human vimentin (MDA-MB-231/brain). Every fourth section of the entire brain was analyzed in two to three different animals 30 to 50 days postinjection. The number of Ki-67-positive and -negative cells was counted for solitary cancer cells and for metastatic lesions containing $>30$ cells. For each of these lesion types, the percentages of Ki-67-positive cells were calculated. SDs and statistical significance were determined by two-tailed Student's t-test.

\section{Quantification of Astrocyte Association with Cancer Cells}

Three days after injection of cancer cells into the carotid artery, the brain tissue was stained for GFAP to detect astrocytes and costained for human CD44(435), human vimentin (231/brain), or GFP (4T1) to detect the cancer cells. The number of reactive astrocytes located within a distance of $150 \mu \mathrm{m}$ from the cancer cells (cancer cell associated) and the number of reactive astrocytes in the corresponding area of the nonafflicted contralateral hemisphere (normal control) was counted for 20 randomly chosen events per brain in two to three animals for each cancer cell line. SDs and statistical significance were determined by two-tailed Student's t-test.

\section{Results}

\section{Models and Kinetics of Initial Cancer Cell Colonization of the Brain}

To define models suitable for studying the earliest steps of cancer cell brain colonization, we injected five different F-luc-tagged breast cancer cell lines into the left internal carotid artery of female immunodeficient or immunocompetent mice and followed cancer cell distribution and 
A

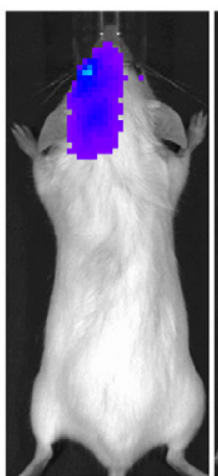

$15 \min$

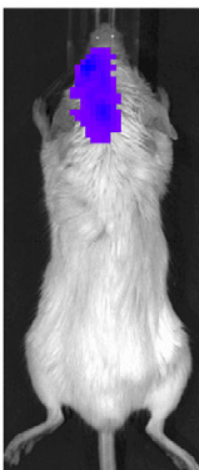

day 2

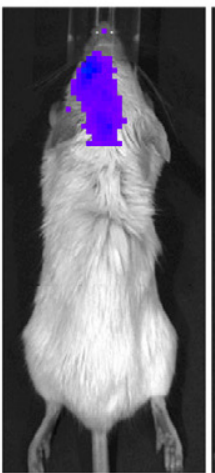

day 4

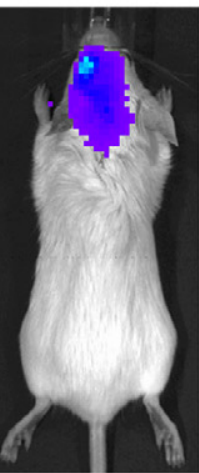

day 6

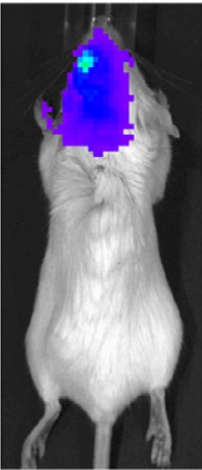

day 8

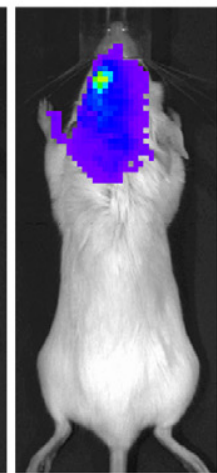

day 10

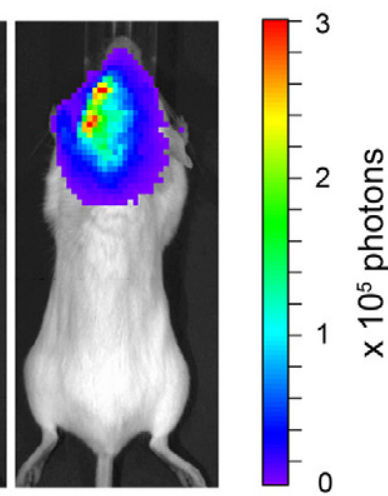

day 14
B

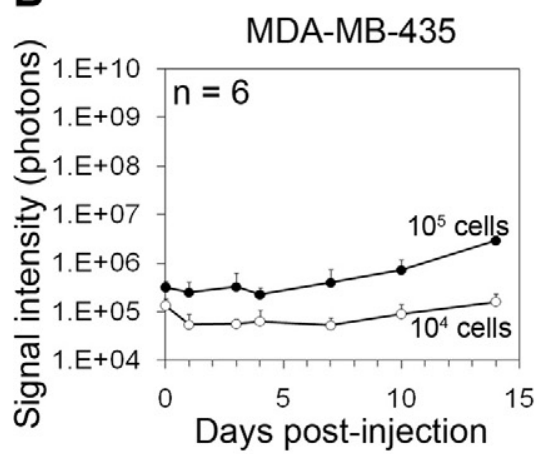

MCF-7

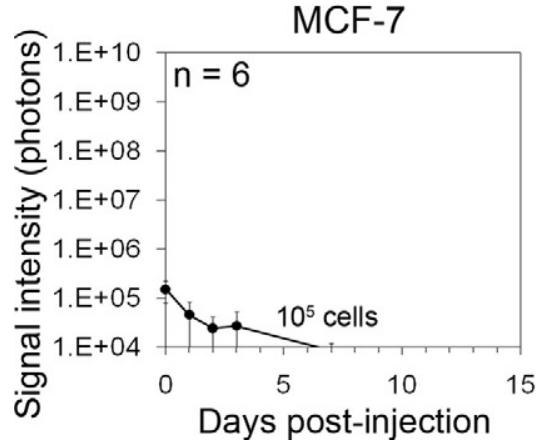

MDA-MB-231/ brain

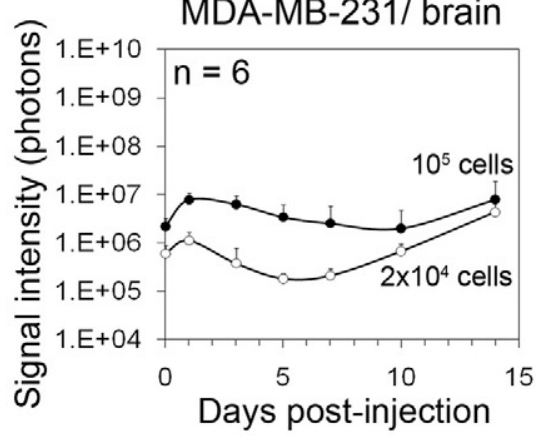

MDA-MB-231

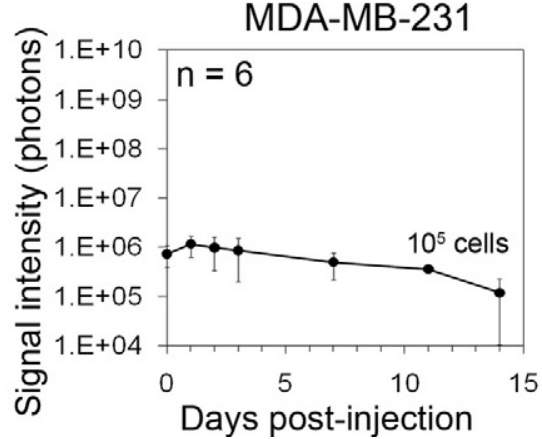

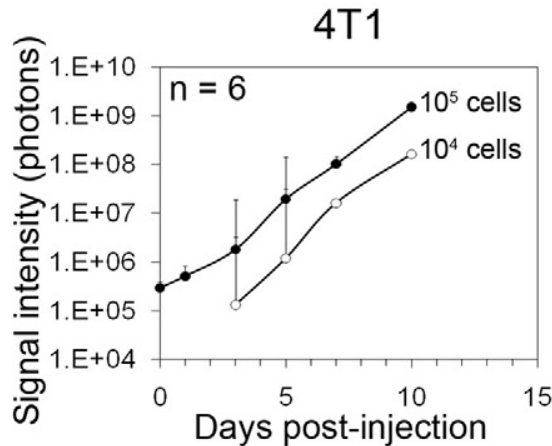

Figure 1. Brain colonization by breast cancer cell lines after carotid artery injection in mice monitored by bioluminescence imaging. A: Increase of bioluminescence signal indicates growth of F-luc-tagged MDAMB- 435 cells shown in a representative animal at various time points after injection of $10^{5}$ cancer cells. B: Survival and growth of F-luc-tagged MDA-MB-435, MDA-MB-231 parental, MDA-MB-231/brain, MCF-7 (injected into immunosuppressed CB17/SCID mice), and $4 \mathrm{~T} 1$ cells (injected into immunocompetent BALB/C mice) after injection into the left carotid artery followed over time. Only live cells produce signal. Number of injected cells as indicated. growth by noninvasive bioluminescence imaging (Figure 1). CB17/SCID mice were used to analyze human tumor cells and BALB/c mice for syngeneic murine 4T1 breast cancer cells. Comparing MDA-MB-435, MDA-MB-231, MDA-MB-231/brain, ${ }^{28} \mathrm{MCF}-7$, and $4 \mathrm{~T} 1$ cells, we found that all five cell lines were detectable within the brain area 15 minutes postinjection. Even though each of these cell lines initially localized to the brain area, only MDA-MB435, MDA-MB-brain/brain, and 4T1 cells produced persistent and increasing signal over time, whereas MDAMB-231 parental and MCF-7 signal declined and eventually disappeared (Figure 1, A and B). Immediately after carotid artery injection of $10^{4}$ or $10^{5}$ MDA-MB-435 cells, strong bioluminescence signal was detected in the left hemisphere of the brain and the signal persisted without major change in intensity through days 5 to 7 , before it increased continuously (Figure 1, A and B). Only live cells produce signal, indicating that the majority of the initially arrested cancer cells remained and survived this step. Just after carotid artery injection of MDA-MB435 cells, a weak tumor cell signal was occasionally seen in the lungs, but this signal disappeared within a few days and never reappeared (data not shown). The signal for MDA-MB-231/brain cells initially decreased slightly, indicating that some of the cancer cells were eliminated. Between days 5 and 10, the remaining signal then began to increase continuously. 4T1 murine breast cancer cells colonized the brain much more aggressively than the two human cell lines. The 4T1 signal started to increase immediately after tumor cell injection and continued to increase at a much faster rate than that of MDA-MB-435 and $231 /$ brain cells.

To investigate the behavior of the bioluminescence producing tumor cells in more detail, we followed individual cells by histology on days 3, 5, and 7. We analyzed the entire brain of each animal by immunohistochemistry at each of these time points ( $n=2-4$ mice per time and cell type). Human tumor cells were detected using two 
independent markers (human CD44 and human vimentin). Murine $4 \mathrm{~T} 1$ cells were identified by their GFP label via anti-GFP staining. We found that MDA-MB-231 parental cells were rapidly cleared from the circulation of the brain parenchyma and were undetectable inside or outside the vasculature of the brain tissue on days 3,5 , and 7 postinjection. Residual bioluminescence signal of MDA-MB-231 parental cells in the brain area seen through day 5 (Figure 1) was likely due to tumor cells in the leptomeninges, which remained attached to the skull when the brains were removed for histology at these early time points. In contrast, MDA-MB-435, MDA-MB-231/ brain, and $4 \mathrm{~T} 1$ cells were readily detected throughout the brain parenchyma very early (eg, days 1, 2, 3, and 7) as well as at later time points. After 10 to 50 days, numerous macrometases were found in $100 \%$ of the animals ( $n=$ 3-6/group) after injecting $10^{4}$ to $10^{5}$ of these tumor cells. $4 \mathrm{~T} 1$ cells exhibited the most rapid growth in their immunocompetent hosts and produced extensive metastatic burden already after 10 days. MDA-MB-435 and brain homing MDA-MB-231/brain cells were previously reported to produce metastatic lesions in the brain when administered into the bloodstream, ${ }^{28,31}$ but the early colonization steps have not been previously investigated. MDA-MB-435 cells are aggressively metastatic breast cancer cells that share some characteristics with melanoma, ${ }^{32,33}$ another tumor type that frequently causes brain metastasis in patients. ${ }^{1}$ The MDA-MB-231/brain cell line was derived from MDA-MB-231 parental breast cancer cells after cardiac injection into immunodeficient mice and six cycles of isolating brain metastases and reinjection into the heart. ${ }^{28}$ Here, we demonstrated that MDAMB-231/brain cells, as well as MDA-MB-435 and 4T1 cancer cells, are suitable models for studying cancer cell interaction with the brain microvasculature even at the earliest time points, for following the ability of cancer cells to survive and grow within the brain tissue, and for analyzing involved host cell responses.

\section{Cancer Cell Extravasation, Growth in the Brain, and Types of Blood Vessels Involved}

To analyze the mode and timing of cancer cell extravasation, their initial proliferation in the brain parenchyma, and the types of blood vessels involved in extravasation and lesion growth, we followed the cancer cells on days 1, 2, 3, 5, and 7 after carotid artery injection by immunohistochemistry.

The localization of cancer cells and blood vessels was determined by staining the human cancer cells with antihuman CD44 (mAb 29.7) (30 $^{30}$ or anti-human vimentin, mouse 4T1 cells with anti-GFP, and the vasculature with anti-CD31 (Figure 2, A-G, and Supplemental Figure 1, see http://ajp.amjpathol.org). During the first 2 days after inoculation, all cancer cells were found inside blood vessels and displayed an elongated shape to fit into the narrow capillaries (Figure 2A). On day 3 postinoculation, for all three cell lines examined, the majority of cancer cells were still localized within the microvasculature (Figure 2, B, H, and I, and Supplemental Figure 1, see http:// ajp.amjpathol.org). Only a small percentage was extravasating (Figure 2, C, H, and I, and Supplemental Figure 1, see $h$ ttp://ajp.amjpathol.org) or already located in the extravascular space, staying close to the vessels from which the cells had emerged (Figure 2D and Supplemental Figure 1, see http://ajp.amjpathol.org). Before or during extravasation, the cancer cells rounded up inside the vascular lumen and formed cytoplasmic protrusions, which apparently expanded the vessel wall that surrounded them (Figure 2B; also see Figure 5C, day 3, blue arrowheads). Intravascular cancer cells penetrating the blood vessel wall with their cytoplasmic protrusions were also detected (Figure 21, middle panel, and Supplemental Figure 1, see http://ajp.amjpathol.org). Extravasation of individual cancer cells seemed to at least occasionally involve larger interruptions of the vessel wall (Figure 2, $\mathrm{C}-\mathrm{F})$. However, we could not detect any apoptosis or hypoxia associated with the endothelium at sites of cancer cell extravasation by terminal deoxynucleotidyl transferase-mediated dUTP nick-end labeling staining or hypoxyprobe, respectively. This suggests that the extravasation events were not associated with significant destruction of the vessel wall (data not shown). However, fibrin formation and platelet aggregation were detected at sites of $4 \mathrm{~T} 1$ cell extravasation in BALB/C mouse brain on days 3,5 , and 7 posttumor cell injection (Figure $2 \mathrm{~J}$ and data not shown). On day 5 postinoculation, 20 to $40 \%$ of the cancer cells were still intravascular (Figure $2 \mathrm{H})$. On day 7 , all MDA-MB-435 and $4 \mathrm{~T} 1$ tumor cells were found in the extravascular space, whereas $\sim 15 \%$ of MDA-MB-231/brain cells were still intravascular, suggesting a slightly slower extravasation kinetics (Figure 2, E-I, and Supplemental Figure 1, see http://ajp.amjpathol.org). At this time, for all three cell lines, small groups of cancer cells were detected close to capillaries or lined up along the vessel wall at the parenchymal side, indicating initial cancer cell growth (Figure 2, F and G, and Supplemental Figure 1, see http://ajp.amjpathol.org). Notably, for MDAMB-435 cells, extravasation always preceded cancer cell proliferation, because groups of two or more cancer cells were seen only in the extravascular space and never inside blood vessels (Figure 2, C-G). In contrast, groups of cancer cells within the vasculature were found for $4 \mathrm{~T} 1$ cells, suggesting that these cells might proliferate even before extravasating. This is in line with the immediate increase in bioluminescence signal for this cell line from day 1 on (Figure 1B).

By days 30 to 70 , all mice injected with MDA-MB-435 or MDA-MB-231/brain cells harbored large metastatic lesions within the brain parenchyma and leptomeninges. At this stage, leptomeningeal metastases remained attached to the brain surface when the brains were harvested, allowing us to analyze these lesions in detail and to compare them to lesions within the brain tissue. Although metastases in the brain parenchyma grew preferentially around capillaries, forming elongated clusters around these small vessels (Figures $2 \mathrm{~K}$ and $3 \mathrm{C}$ ), leptomeningeal lesions were compact nodules and contained capillaries as well as larger vessels (Figure 3C).

Because of the rapid intracranial growth of $4 \mathrm{~T} 1$ cells, these experiments were terminated after 10 to 14 days. 


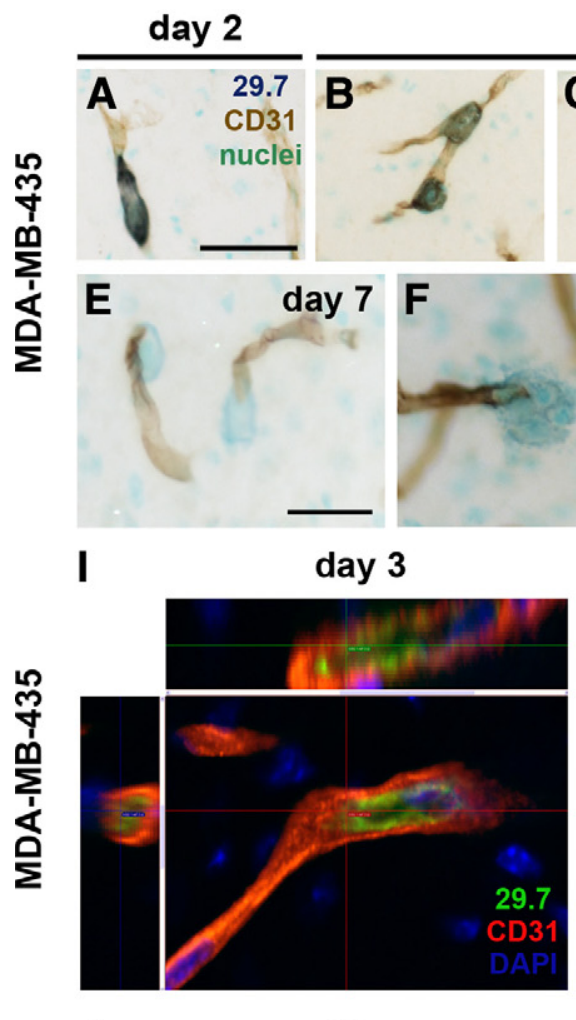

$\mathbf{J}$ day 3

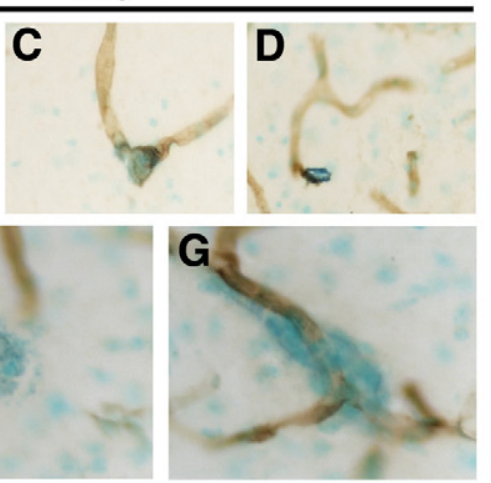

day 3
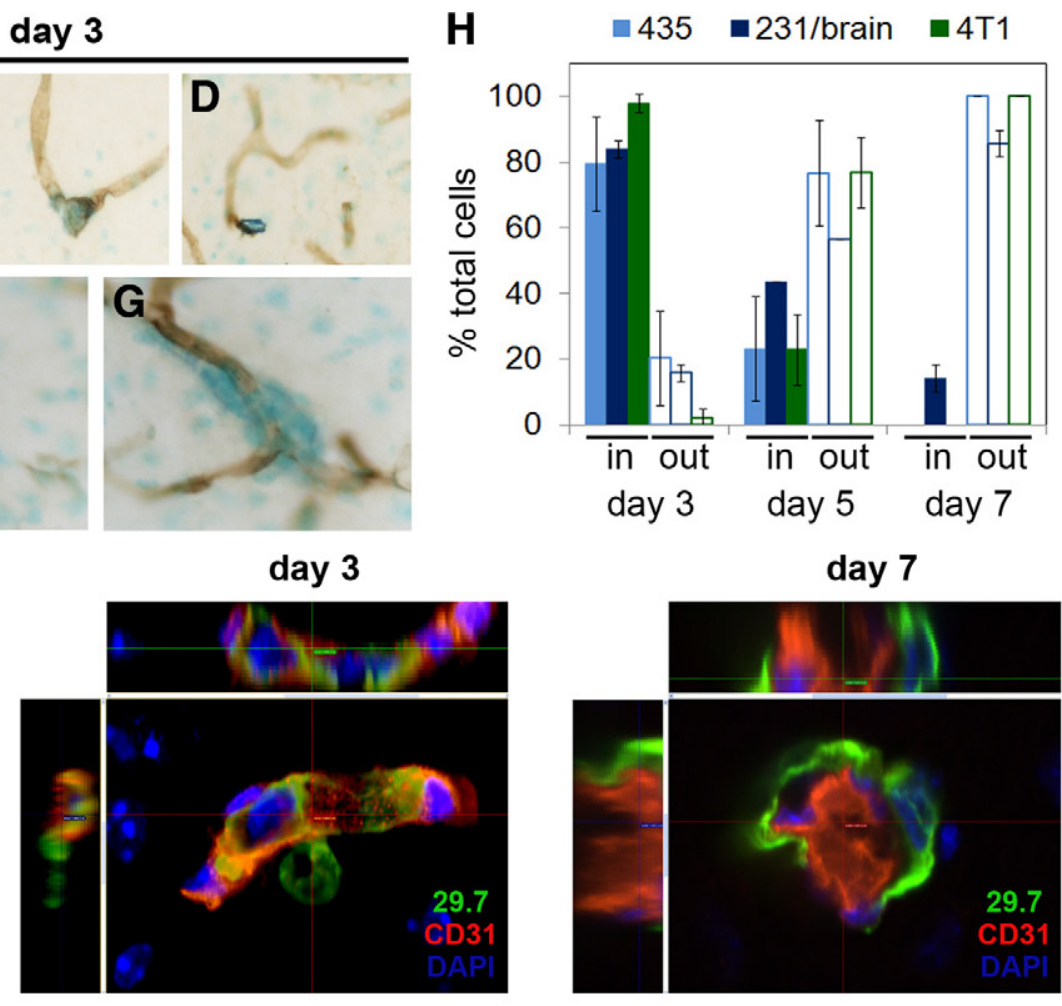

M
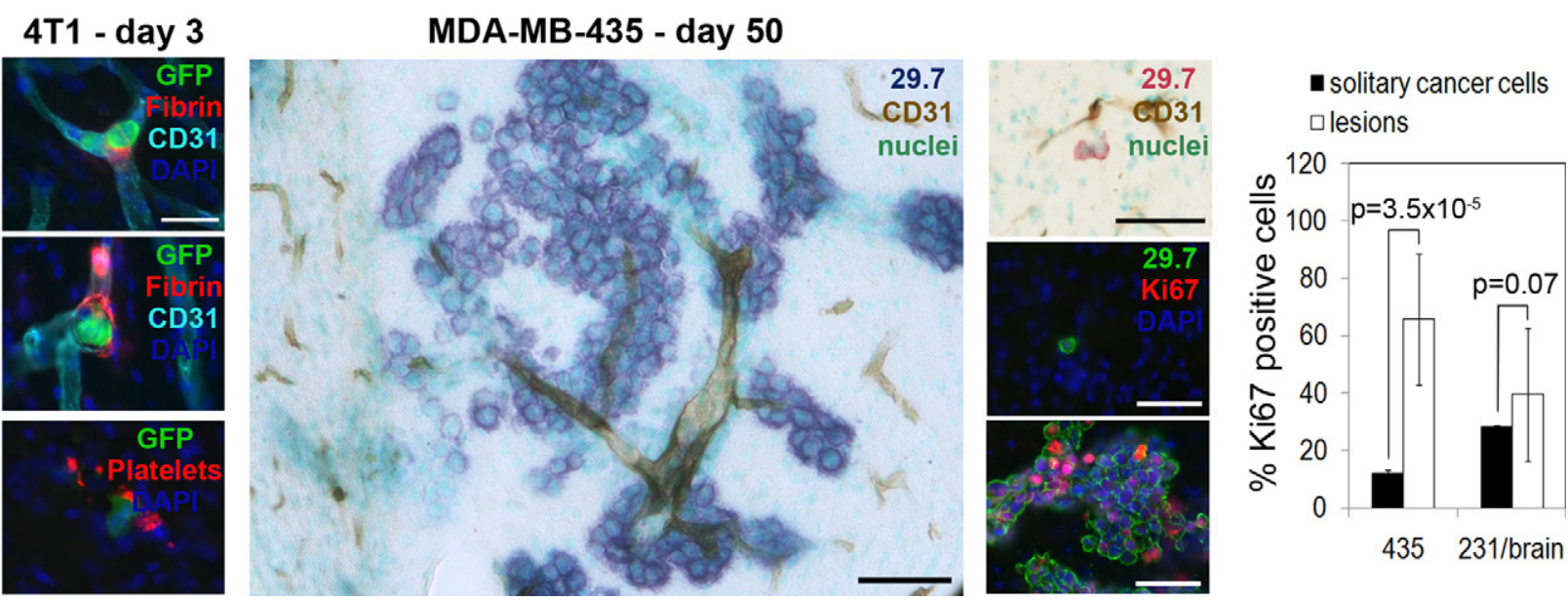

Figure 2. Cancer cell extravasation and growth in the brain. A-G: MDA-MB-435 cells were visualized by anti-human CD44 (mAb 29.7$)$ and blood vessels by CD31 staining using immunohistochemistry. A: An elongated cancer cell within a capillary on day two postinjection. B: Rounding of intravascular cancer cells on day three. C: Cancer cell on day three breaking through the vessel wall during extravasation. D: Extravasated cancer cell on day three. E-G: Extravascular cancer cells on day seven. Scale bars: $50 \mu \mathrm{m}(\mathbf{A}-\mathbf{D}) ; 25 \mu \mathrm{m}(\mathbf{E}-\mathbf{G})$. H: Percentage of cancer cells located inside versus outside blood vessels. The quantification was performed for three different cells lines: MDA-MB-435, MDA-MB-231/brain, and 4T1. I: Analysis of early cell location by confocal microscopy. Cancer cells were stained for human CD44 (green) and blood vessels for CD31 (red). An intravascular cell (left panel), a cell in the process of extravasation (middle panel), and extravascular cells (right panel) are shown. J: Association of intravascular $4 \mathrm{~T} 1$ cancer cells with fibrin and platelets (GPIb $\alpha$ staining) on day three. Scale bar: $25 \mu \mathrm{m}$. K: Day 50: Long-term fate of MDA-MB-435 cells was monitored by immunohistochemistry. Intraparenchymal macrometastases grew preferentially around co-opted blood vessels. Scale bar: $200 \mu \mathrm{m}$. L: Solitary tumor cells outside blood vessels on day 50 (top panel), detected by anti-human CD44 (mAb 29.7), are mostly negative for Ki-67 (middle panel). In contrast, most cells within lesions as shown in K are Ki-67 positive (bottom panel). Scale bars: $50 \mu \mathrm{m}$. M: Quantification of Ki-67-positive cells within the solitary cancer cell population and within the macrometastatic lesions for MDA-MB-435 and MDA-MB-231/brain cells 30 to 50 days postinjection.

All animals harbored numerous macrometastases, tightly lined up along blood vessels within the brain parenchyma. No obvious leptomeningeal lesions were observed for this cell model.

During the initial steps of brain colonization within the parenchyma, cancer cells exclusively arrested within and extravasated from capillaries and/or postcapillary venules. These vessels were identified by immunohistochemistry based on their size and lack of smooth muscle cells (Figure 3A). The vessels were positive for CD31 as well as for CD34 and were surrounded by platelet-derived growth factor receptor $\beta$-positive peri- 
A

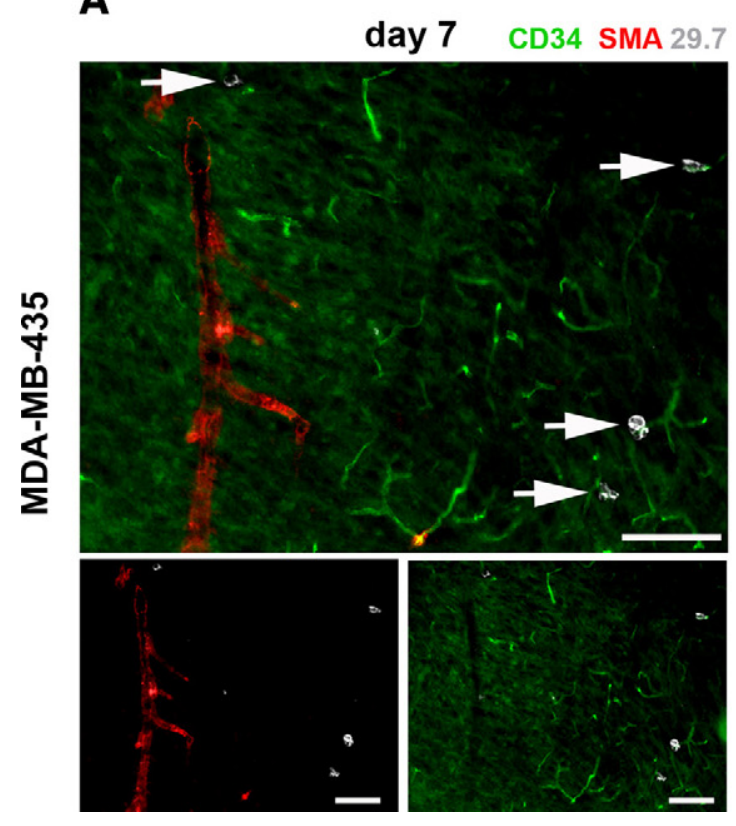

B

Lectin PDGFRb 29.7
C
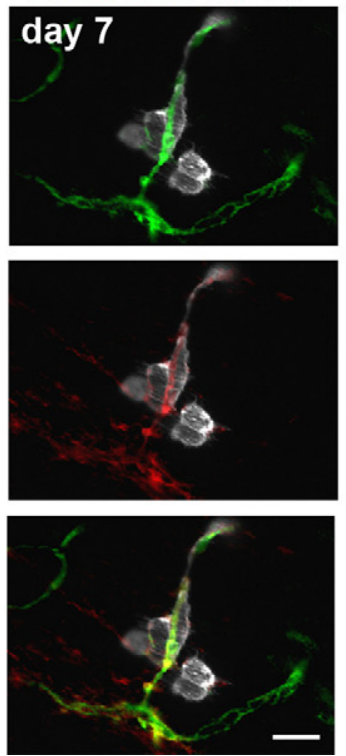

day 50 CD34 SMA 29.7
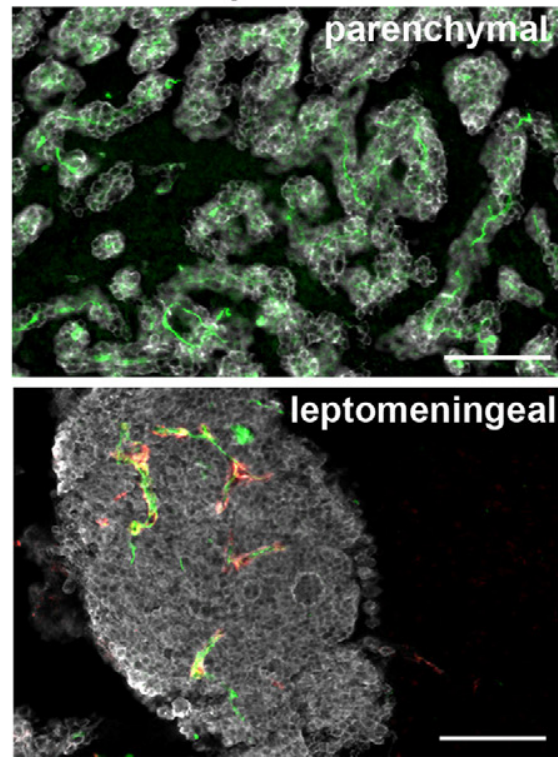

Figure 3. Blood vessel types involved in cancer cell extravasation and growth. Blood vessel types were analyzed by immunofluorescence. Representative images for MDA-MB-435 cells are shown. A: Day seven: in the brain parenchyma, cancer cells (white, arrows) arrest and extravasate exclusively from capillaries or postcapillary venules positive for CD34 and lacking smooth muscle cells (no smooth muscle actin (SMA) signal). Scale bars: $100 \mu \mathrm{m}$. B: Day seven: blood vessels from which cancer cells (gray) extravasate are surrounded by platelet-derived growth factor receptor $\beta$ (PDGFRb)-positive pericytes. Top panel: BS-1 lectin; middle panel: anti-PDGFRb; and bottom panel: merge. Scale bar: $20 \mu \mathrm{m}$. C: Day 50: intraparenchymal metastases grow around co-opted capillaries lacking smooth muscle cells. Leptomeningeal metastases contain capillaries as well as larger, smooth muscle cell-positive vessels. Scale bars: $100 \mu \mathrm{m}$.

cytes (Figure 3B). This indicates that parenchymal lesions stayed associated with the vessel type from which they initially emerged.

In addition to successfully growing large metastatic lesions, we detected many single cancer cells scattered throughout the brain at late time points for MDA-MB-435 and 231 /brain cell models (days 30 to 70 postinjection). These cells were localized within the brain parenchyma next to capillaries (Figure 2L, top panel). The majority of the solitary MDA-MB-435 cancer cells were not proliferating, as only $12 \%$ of these cells were positive for cell cycle marker Ki-67 (Figure 2, L, middle panel, and M). Thus, these solitary cancer cells were arrested in $G_{0}$ of the cell cycle and remained dormant after extravasation, whereas the majority of cancer cells within larger lesions (63\%) were Ki-67 positive and proliferated actively (Figure 2, L, bottom panel, and M). In contrast, there was no significant difference in the percentage of Ki-67-positive cells between the solitary cancer cell population and macroscopic lesions for MDA-MB-231/brain cells (Figure 2M). Notably, no solitary cancer cell population was detected for the aggressive murine 4T1 breast cancer cell line in their syngeneic BALB/c host model. All observed 4T1 cells grew in tight clusters around blood vessels 10 days after carotid artery injection (data not shown).

\section{Cancer Cell Arrest and Extravasation in the Brain Induce Diverse Microglial and Astrocyte Responses}

It is well established that the host microenvironment affects tumor growth and metastatic progression and im- pacts the success of tumor cells to survive and grow within the brain. ${ }^{6,29,34-36}$ Therefore, we investigated the earliest responses of brain residing cells to incoming cancer cells during the initial steps of hematogenous brain metastasis. A major cell type of the brain known to respond to invading cells from the immune system during inflammatory brain disease and development of primary brain tumors is microglia. ${ }^{14-18}$ We therefore investigated an involvement of microglia in the earliest steps of cancer cell brain colonization. F4/80 was used as a marker for microglia and macrophages. Our analysis revealed a varying accumulation of F4/80-positive cells with strongly increased F4/80 expression, indicative of microglial activation, around extravasated cancer cells on day 7 in all three cancer cell models (MDA-MB-435: Figure 4A-G; 4T1: Figure 4H-K; MDA-MB-231/brain: data not shown). Similar microglial responses were observed in immunosuppressed SCID mice and immunocompetent BALB/C mice. Some cancer cells that had left the vasculature recruited large amounts of activated microglia, whereas only few or no activated microglial cells could be detected in the vicinity of other cancer cells (Figure 4, A and $\mathrm{H}$, left panel). However, the microglial responses observed were specifically induced by the cancer cells, and were not a consequence of the surgical manipulation since activated microglial cells were never detected in the same brain regions of animals injected with medium alone (Figure $4 \mathrm{H}$, right panel). Microglia associated with the initial micrometastases presented either as activated microglia displaying characteristic stellate morphology with thick cellular processes (Figure 4, D and J) or as reactive microglia with typical amoeboid morphology ${ }^{37}$ 
day 7

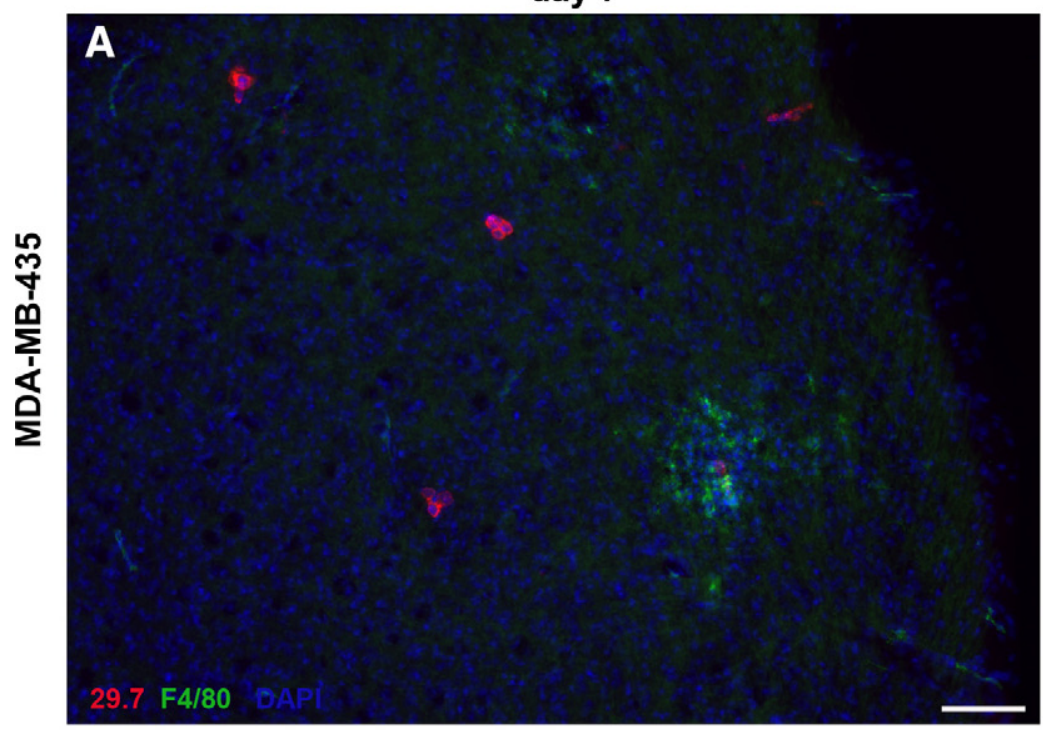

day 7
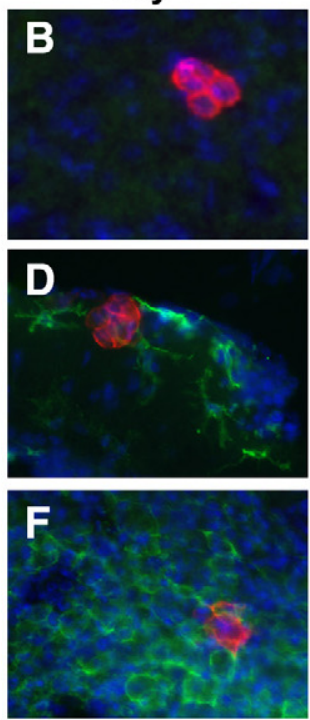

day 50
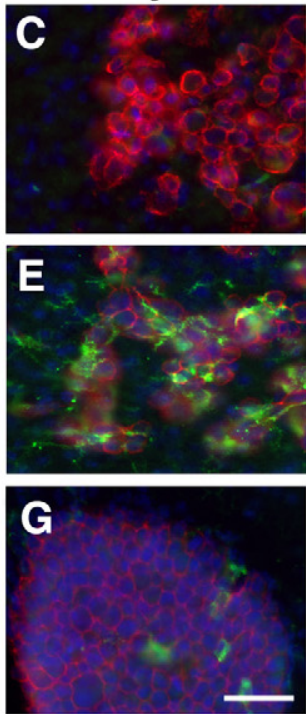
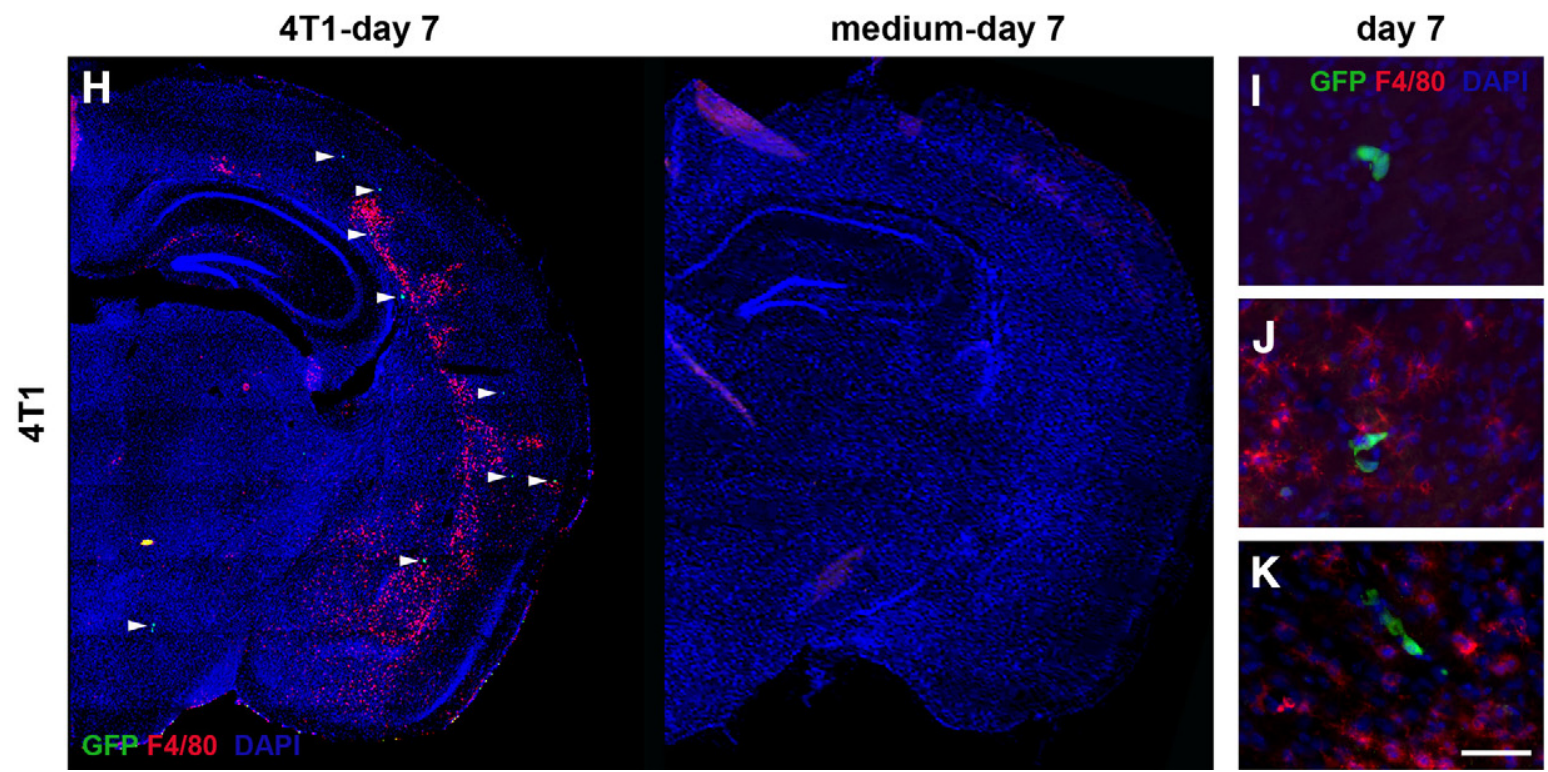

Figure 4. Microglial cell responses to invading cancer cells are heterogeneous. Microglial activation in response to cancer cell invasion varies at early as well as late stages, as detected by immunofluorescence analysis. A-G: MDA-MB-435 cells in immunosuppressed mice; diverse microglial responses (green) to incoming cancer cells (red) on day seven (A). Responses include absence of microglial cells (B), presence of hypertrophic stellate activated (D), or amoeboid reactive microglial cells (F). Similarly, on day 50, some macrometastases show no microglial involvement (C) or contain stellate (E) or amoeboid microglia (G). Scale bars: $100 \mu \mathrm{m}(\mathbf{A}) ; 50 \mu \mathrm{m}(\mathbf{B}-\mathbf{G})$. H-K: 4T1 cells in immunocompetent mice; H: distribution of activated microglia (red) in the mouse brain seven days after carotid artery injection of cancer cells (left panel) or medium alone (right panel). White arrowheads mark the GFP-labeled cancer cells (green). Diverse microglial responses to cancer cells include absence of microglial cells $(\mathbf{I})$, presence of hypertrophic stellate $(\mathbf{J})$, or reactive amoeboid microglial cells $(\mathbf{K})$. Scale bar: $50 \mu \mathrm{m}$.

(Figure 4, F and $\mathrm{K}$ ). The heterogeneity in microglial responses persisted throughout metastatic lesion development. Even macrometastases on day 50 posttumor cell injection were either completely free of microglial cells (Figure 4C) or found associated with activated stellate (Figure 4E) or reactive amoeboid microglia (Figure 4G). Thus, microglial responses to brain invading cancer cells can generate a variety of local microenvironments that may affect lesion growth. These responses could be dynamically regulated, potentially explaining their sporadic detection.

In addition to the variable microglial responses, astrocytes and their activation were consistently found associated with invading cancer cells from the earliest intravascular arrest steps on (Figure 5). In addition to pericytes, brain capillaries are supported by astrocytes, which contribute to the tightness and functions of the blood-brain barrier. ${ }^{38-40}$ After interacting with endothelial cells, pericytes and astrocytes are the first host cell types that extravasating cancer cells encounter. Strikingly, in all three cancer cell models, arrest and extravasation of cancer cells consistently resulted in a strong local activation of astrocytes, detected by the up-regulation of GFAP as well as by the hyperdilation of astrocyte processes (MDA-MB-435: Figure 5, A and C; 4T1: Figure 5D; MDA-MB-231/brain: data not shown). 
A

MDA-MB-435-day3

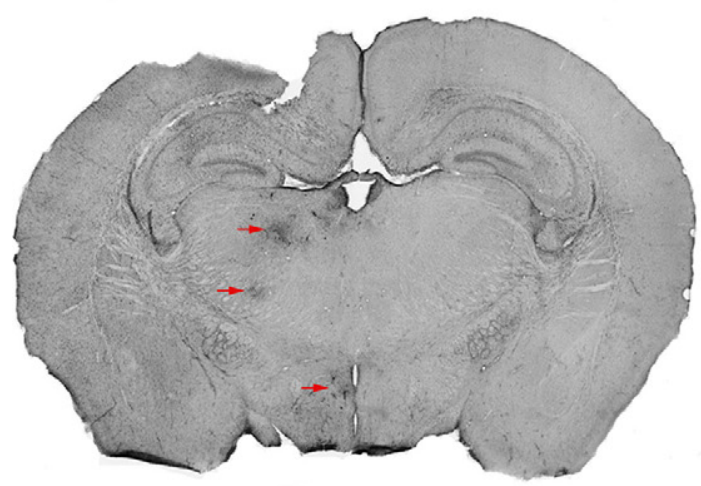

medium-day3

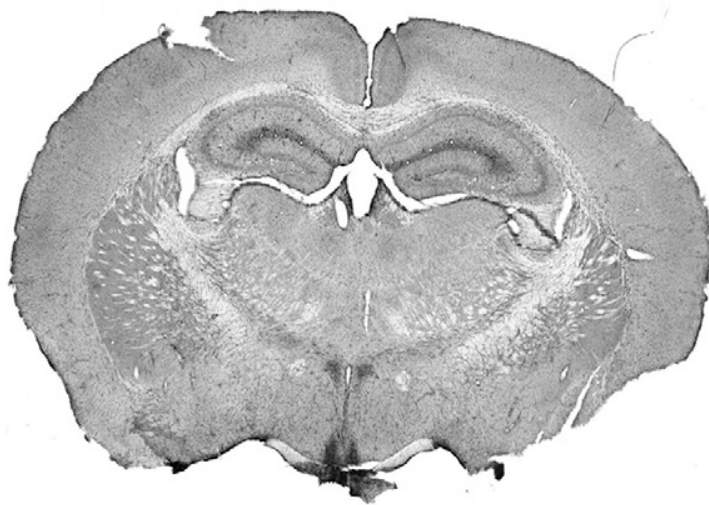

D 4T1

B associated 口normal control

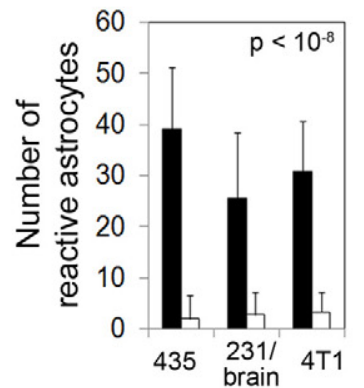

MDA-MB-435

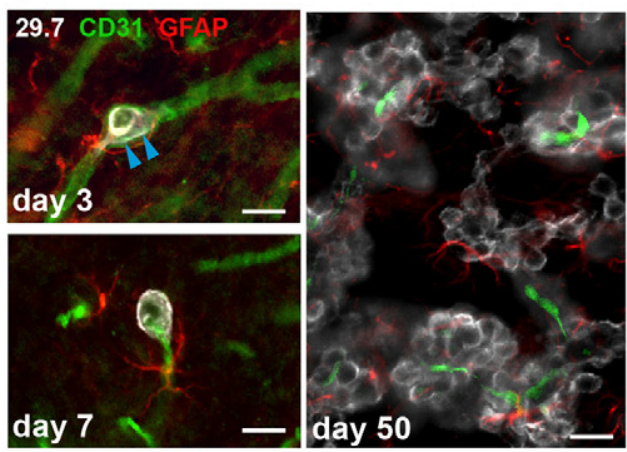

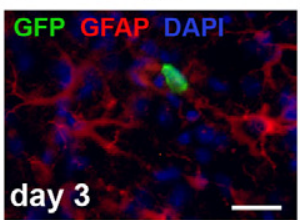

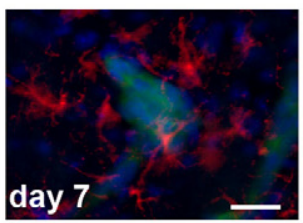

E
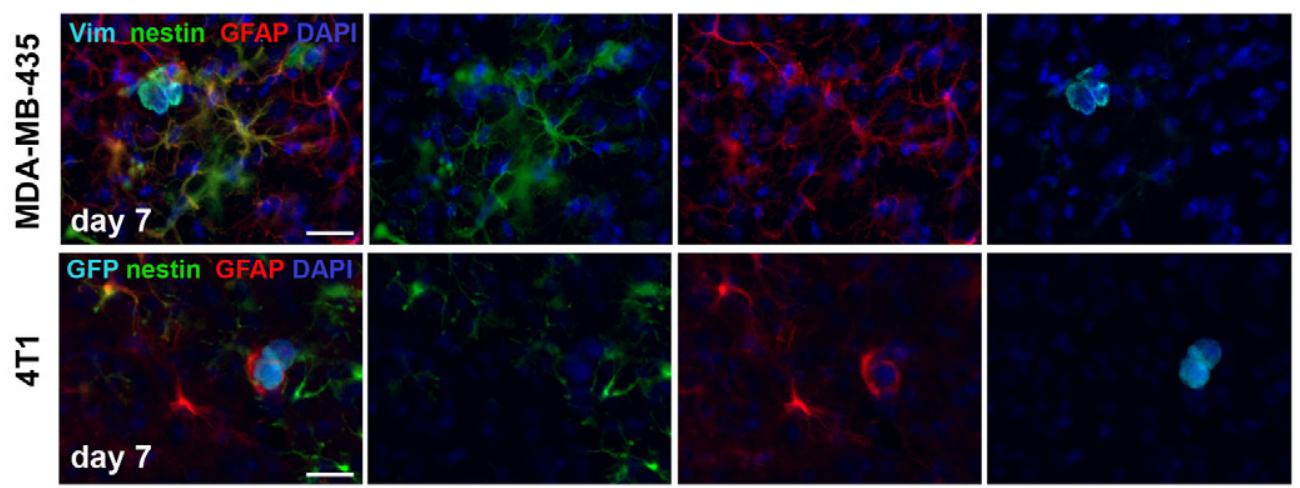

$\mathbf{F}$
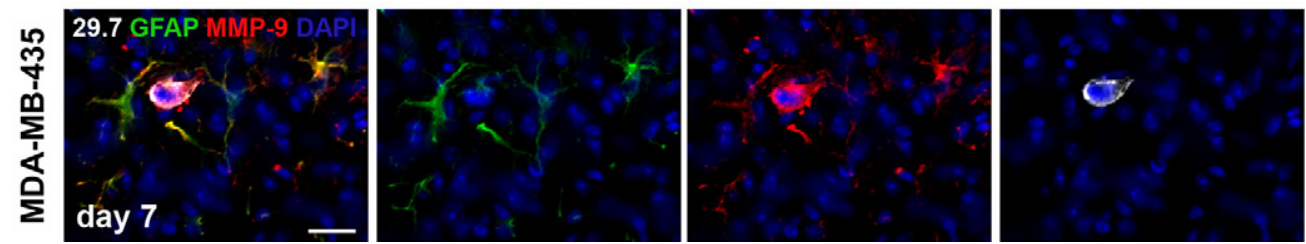

Figure 5. Cancer cell invasion induces strong astrocytic responses. Astrocytes were investigated by immunofluorescence staining. A: Left, On day three after cancer cell injection into the left carotid artery, GFAP in astrocytes is already up-regulated strongly in the vicinity of intravascular arrested cancer cells (MDA-MB-435, red arrows). Astrocyte activation can be detected in the left hemisphere in brain overview sections, whereas the corresponding area of the contralateral hemisphere is devoid of GFAP reactivity. Right, Also, no GFAP activity was found in the brain of control animals injected with medium alone. B: Number of reactive astrocytes three days after carotid artery injection of cancer cells, quantified within the 150- $\mu \mathrm{m}$ distance from cancer cells (cancer cell associated) and within the corresponding region of the contralateral hemisphere that lacks cancer cells (normal control). C: Activated astrocytes with thick processes and up-regulated expression of GFAP are detected next to MDA-MB-435 cancer cells that are still intravascular. Note the cytoplasmic protrusions of cancer cells on day three postinoculation that apparently cause stretching of the vessel wall (blue arrowheads) (day three, upper left panel). GFAP-positive astrocytes stay close to extravasated tumor cells (day seven, lower left panel). Reactive astrocytes persist close to cancer cells throughout their development into macrometastases (day 50, right panel). Scale bars: $20 \mu \mathrm{m}$. D: Activated astrocytes are also present in the vicinity of $4 \mathrm{~T} 1$ breast cancer cells injected into the carotid artery of syngeneic BALB/c mice. Scale bars: $20 \mu \mathrm{m}$. E: In addition to GFAP up-regulation, some reactive astrocytes simultaneously express nestin Merged images are shown on the left. Human vimentin or GFP (light blue), nestin (green), GFAP (red), and 4',6'-diamidino-2-phenylindole (DAPI) (dark blue). Scale bar: $20 \mu \mathrm{m}$. F: Strong up-regulation of MMP-9 is detected in reactive astrocytes located in the immediate vicinity of extravasated MDA-MB-435 tumor cell. Scale bar: $20 \mu \mathrm{m}$. 
Astrocyte activation was always and exclusively seen in close proximity of cancer cells. In many cases, the astrocyte response was so strong that it could be detected in overviews of whole brain sections, even on day 3 postcancer cell injection (Figure 5A). At this stage, reactive astrocytes were present in close proximity of individual cancer cells, even before those extravasated (Figure 5C, day 3). Reactive astrocytes persisted throughout the extravasation process (Figure 5, C and D, day 7) and establishment of large metastatic lesions (Figure 5C, day 50). Early astrocyte activation on day 3 was a specific response to the presence of cancer cells, because the injection of medium alone in sham operated animals did not result in any detectable astrocyte activation (Figure 5A). Furthermore, no increase in reactive astrocytes was observed for the corresponding brain area in the contralateral brain hemisphere (Figure 5A). Notably, injection of breast cancer cells into the left internal carotid artery resulted in tumor cell colonization of only the left hemisphere of the brain, whereas the right hemisphere remained unaffected. We therefore used the right tumor cell-free hemisphere as a control to quantify the number of reactive astrocytes associated with cancer cells in the left hemisphere. The results demonstrate a significant and specific increase in reactive astrocytes in the proximity of cancer cells on day 3 postinjection for all three breast cancer cell models (Figure 5B).

In addition to elevated expression of GFAP, some cancer cell-associated astrocytes simultaneously up-regulated expression of nestin, another marker of reactive astrocytes $^{41}$ (Figure 5E). We confirmed that nestin staining was truly associated with astrocytes by costaining blood vessels and microglia with nestin (Supplemental Figure 2, see http://ajp.amjpathol.org). This result reflects a diversity of atrocytic responses to tumor cells.

An important consequence of astrocyte activation is their ability to secrete factors such as MMP-9. ${ }^{42,43}$ MMP-9 can directly impact cancer cell invasion and has known proangiogenic and growth-promoting functions in brain tumors through release of growth factors from the extracellular matrix. ${ }^{34}$ We found a strong expression of MMP-9 by MDA-MB-435 cells as well as a strong up-regulation of MMP-9 protein in the immediate vicinity of extravasating cancer cells, associated with activated astrocytes that surrounded the tumor cells (Figure 5F). Another factor also known to be released by reactive astrocytes is SDF-1, ${ }^{44-47}$ but we did not detect SDF-1 in the context of astrocyte responses to cancer cell invasion (data not shown). Taken together, astrocytes might provide early and continuous proangiogenic and/or survival signals that support cancer cell growth. The mechanism might involve release of MMP-9 into the immediate proximity of the cancer cells. Because of their consistent and very early response to arriving cancer cells in the brain and the persistence of their association with proliferating tumor cells, astrocytes might provide a supportive microenvironment for the development of brain metastatic lesions.

\section{Discussion}

The present study provides detailed in vivo analyzes of breast cancer cell arrest and extravasation into the brain parenchyma. Furthermore, it captures the diversity of early host responses within the brain microenvironment during the initial steps of cancer cell invasion. Information on the first interaction between brain-homing tumor cells and reactive host cell types will contribute to a better understanding of critical early events in brain metastasis. This insight may help develop strategies for prevention and treatment of symptomatic brain lesions.

Our results show that breast cancer cells arrest exclusively in brain capillaries and/or postcapillary venules. Comparing five different breast cancer cell models, we identified three as suitable models for detailed studies of the earliest critical events of breast cancer cell extravasation and initial brain colonization. Importantly, only these tumor cells consistently developed metastatic lesions. Reports in the literature differ on the time course of cancer cell extravasation, likely because of the use of different cancer cell types, routes of inoculation, and primarily because of distinct microvascular structures within the target organs examined. In general, it takes significantly longer for cancer cells to extravasate into the brain parenchyma than into other organ tissues. For example, extravasation of lung cancer cells in the brain was reported to take 48 hours, whereas the same tumor cells extravasated into the liver within only 6 hours. ${ }^{13}$ In another study, prostate cancer cells derived from brain metastases apparently remained inside brain capillaries for up to 5 days. ${ }^{27}$ In our approach, breast cancer cells were injected into the left internal carotid artery of immunosuppressed SCID mice or immunocompetent BALB/C mice. Importantly, we found that regardless of the host immune state, the timing of tumor cell arrest within the vasculature and extravasation was the same for all tumor cell models examined. We found the tumor cells arrested within the brain microvasculature and in the process of extravasation from day 3 on. Extravasation was completed on day 7 , except for MDA-MB-231/brain cells, where a small percentage of cells was still intravascular. Thus, arrested cancer cells apparently have to survive within the brain vasculature for a significantly longer period of time than in other organs. Cancer cell survival in the vasculature is likely a critical step that limits the success rate of brain metastasis. This step is probably influenced by the ability of cancer cells to specifically interact with components of the vessel wall on arrest. In line with this concept, it was recently reported ${ }^{27}$ that the majority of DU145/RasB1 prostate cancer cells, which arrested in the brain vasculature, were eliminated before they could extravasate, pointing at intravascular survival as a rate limiting step. These studies were performed in immunodeficient mice. The presence of a fully competent immune system, especially natural killer cells, ${ }^{48}$ is expected to pose additional survival pressure on cancer cells that remain arrested within the vasculature for extended periods of time. However, our results indicate that arrested breast cancer cells can survive for several days within the cerebral microvasculature in the presence of a 
fully functional immune system. We found that $4 \mathrm{~T} 1$ cells injected into BALB/c mice initiated growth very rapidly without any signs of cancer cell death by terminal deoxynucleotidyl transferase-mediated dUTP nick-end labeling staining (data not shown). In this model, we observed platelet accumulation and fibrin formation associated with intravascular cancer cells, potentially protecting them from the immune system.

Compared with the brain, intravascular survival may be less critical in other organs because of significantly shorter extravasation times. Recently, Bos et al ${ }^{49}$ identified genes that promote breast cancer brain metastasis through a gene profiling analysis. Importantly, these genes make up a group of mediators of cancer cell extravasation in an in vitro model of the blood-brain barrier. Notably, the duration of transendothelial migration by cancer cells in vitro is significantly shorter (6 to 18 hours) than that required for extravasation into brain tissue in vivo ( 3 to 5 days). Furthermore, conditions in the vasculature are much more complex than can be recapitulated in vitro. Although one can envision extravasation as a ratelimiting step for cancer types that are able to survive after arresting within the cerebral microcirculation, our results indicate that survival factors-in addition to mediators of extravasation-likely play a decisive role in the establishment of brain metastases.

Different modes of cancer cell extravasation have been described. These include extravasation of individual tumor cells without observable disruption of the microvasculature as well as intravascular cancer cell proliferation, followed by eventual vessel rupture, as reported for lung metastasis. ${ }^{50-53}$ In the MDA-MB-435 model, we observed individual cancer cells within brain capillaries that initially assumed an elongated shape to fit into the significantly smaller vessels. Three days later, the tumor cells regained a round shape, thereby stretching the vessel wall. In some cases, the vessels appeared disrupted on extravasation. However, the absence of any detectable apoptosis or hypoxia associated with the vascular endothelium at these sites suggests that no significant damage of blood vessels occurs during the extravasation process. Notably, we also observed cancer cell protrusions stretching through the vessel wall, indicating that crossing of the blood-brain barrier is an active, specific process initiated by the tumor cells. For MDA-MB-435 cells, we did not observe any intravascular proliferation. Groups of two or more cells appeared only in the extravascular space from day 5 on. Consistent with the histology, bioluminescence signal intensity reflecting the number of F-luc-tagged cancer cells started to increase between days 5 and 7 when all of the cells had extravasated. In contrast, we observed intravascular groups of cells for both MDA-MB231/brain and $4 \mathrm{~T} 1$ cells, indicating that these might proliferate before extravasation. This finding correlates with the strong, immediate increase in bioluminescence signal for both MDA-MB-231/brain and 4T1 cells within the first day after injection. For MDA-MB-231/brain cells, the signal intensity decreased after day 1 , before it began to increase continuously between days 5 and 10, indicating that cancer cells were eliminated from the brain vasculature between days 2 and 5 . Exit of cancer cells from capillaries or postcapillary venules may involve mechanical forces caused by rounding of the cancer cells, formation of cytoplasmic protrusions, and most likely secretion of disruptive enzymes such as MMP-9 and heparanase or their combinations. ${ }^{6,12,36,54}$ To our knowledge, only one study previously captured cancer cells in the process of extravasation into the brain, using a rat hepatoma cell line as a model. ${ }^{12}$ In that model, extravasation apparently involved breaching or destruction of the endothelium. The results from our study with breast cancer cells suggest that different modes of extravasation for cancer cells in the brain might exist.

As lesions progressed, we observed macrometastases within the brain parenchyma as well as in the leptomeninges. These locations represent distinct microenvironments within the brain, ${ }^{7,36}$ which we found reflected by strikingly different phenotypes of parenchymal versus leptomeningeal metastases in our models. Throughout their development, metastases in the parenchyma grew mostly around small blood vessels similar to a phenotype reported previously. ${ }^{9,11,27,55}$ We identified these vessels as capillaries or postcapillary venules based on their size and lack of smooth muscle cells. In contrast, metastases in the leptomeninges grew into dense solid lesions that always contained larger vessels surrounded by smooth muscle cells. Because of the fragility of the leptomeninges and their tendency to stay associated with the skull when the brains were removed early after cancer cell injection, our analysis of the initial colonization events focused on the parenchymal microenvironment. It is possible that the first steps of cancer cell arrest and extravasation within leptomeninges differ from the events seen within the brain parenchyma.

The brain is a very specialized environment with a unique cellular composition. Recent evidence suggests that adhesion of cancer cells to components of the vascular basement membrane provides essential survival cues for cancer cells, early during brain colonization. ${ }^{9}$ In addition to initial signals from tumor cell adhesive interactions with the vessel wall, host cells in the immediate microenvironment of the tumor cells are most likely to impact their fate and ability to progress. In our study, we focused on host cell responses to the invading tumor cells. For established brain metastases, it has been well documented that reactive astrocytes and microglia surround the lesions. ${ }^{15,22}$ Furthermore, it is known that glial cells are activated in a response to brain injuries. However, responses of glial cells and astrocytes to the initial stages of tumor cell invasion have not been reported previously. We found that cancer cell arrest, extravasation, and invasion of the brain parenchyma always induced a strong local activation of astrocytes and activation of microglia to varying degrees. Astrocytic responses were heterogeneous in their intensity and cellular composition, involving cells with up-regulated expression of GFAP, nestin, or both. Reactive astrocytes occasionally strongly up-regulated expression of MMP-9, which is known to promote growth of primary brain tumors based on its proangiogenic activity by releasing vascular endothelial growth factor from the surrounding matrix. ${ }^{34}$ In addition, vascular endothelial growth factor can also 
directly stimulate the proliferation of cancer cells. ${ }^{56}$ Furthermore, astrocytes were shown to support brain metastatic growth by secretion of heparanase ${ }^{24}$ and neurotrophins. ${ }^{23}$ Thus, reactive astrocytes may provide initial cues for extravasating tumor cells to survive and proliferate within the brain parenchyma.

Some reactive astrocytes in the vicinity of cancer cells expressed nestin. Nestin is a marker of neuroepithelial stem cells, radial glia cells, and progenitor cells and is down-regulated during terminal differentiation to mature astrocytes. Nestin up-regulation in reactive astrocytes was found associated with brain injury from different causes. ${ }^{41,57-59}$ It has been long debated whether reactive astrocytes originate from progenitor cells that migrated from the subventricular zone or whether they derive from regional mature astrocytes. Recently, several groups showed that nestin-positive subventricular zone progenitors migrate to damaged areas in the brain cortex. ${ }^{60,61}$ Other groups demonstrated that mature astrocytes locally resume proliferation and dedifferentiate in response to brain injury and other stimuli..$^{57,62}$ Thus, both scenarios can occur. In our study, nestin-positive reactive astrocytes were observed very early during cancer cell invasion of the brain parenchyma. The origin of these astrocytes remains to be elucidated.

The reactions of microglia to cancer cells were also diverse. In the normal brain, resting or ramified microglia with thin processes are distributed throughout the brain tissue. On stimulation, ramified microglia can be progressively converted into active microglia via at least two different and functionally distinct morphological states. These are termed activated and reactive microglia. ${ }^{37}$ Although activated microglia express only major histocompatibility complex class I, reactive microglia express both major histocompatibility complex class I and major histocompatibility complex class II and show phagocytic activity. The microglial population we found associated with cancer cells was heterogeneous and consisted of both activated microglia with typical hypertrophic stellate appearance and reactive microglia with amoeboid cell morphology. Notably, microglial responses to cancer cells were similar in immunosuppressed and in immunocompetent mice. Microglial cells can have protective as well as cytotoxic functions. ${ }^{21,22}$ Thus, in addition to astrocytes, microglia may influence tumor cell survival and development into macrometastases.

In addition to macrometastases, we detected many solitary tumor cells distributed throughout the brain parenchyma, 30 to 70 days after carotid artery injection of MDA-MB-435 and MDA-MB-231/brain cells. The vast majority of solitary MDA-MB-435 cells were negative for Ki-67 antigen, indicating their dormant state. In contrast, solitary MDA-MB-231/brain cells and macroscopic lesions displayed similar Ki-67 expression. These observations are in line with previous reports demonstrating that cancer cells have different fates after arresting within the brain vasculature, as they may proliferate and progress to macrometastases, survive without growing (dormancy), or die and become eliminated. ${ }^{63,64}$ In addition to the impact of clonal heterogeneity of cancer cells, local differences within the brain microenvironment, including large molecular diversity between astrocytes in different regions of the brain, ${ }^{65,66}$ may influence the tumor cell fate. These parameters are known to affect neurogenesis and impact melanoma brain metastasis. ${ }^{7,35,67}$ Our results demonstrate that in addition to these locationspecific diversities, the invasion of brain tissue by individual cancer cells induces a variety of glial responses that add to the uniqueness of each local microenvironment. Distinct glial responses may help explain why cancer cells that arrested in the microvasculature can have different fates, even if they are located within the same brain area. ${ }^{63,64}$ Functional contributions of different astrocytic and microglial cell populations to very early steps of metastatic invasion remain to be elucidated. Unraveling the underlying mechanisms in vivo might lead to targeted manipulation of the brain microenvironment for clinical inhibition of brain metastasis. Similar approaches have already been used to convert a nonneurogenic into a neurogenic environment to promote neuron formation in the adult brain. ${ }^{67,68}$ Thus, in the future, one could envision application of these principles for treatment of brain metastasis.

\section{Acknowledgments}

We thank Hwajin Lee for his help with cutting brain cryosections, Karin Staflin for the introduction to the floating sections staining technique, Heiko Wurdak for help with confocal microscopy, and James Quigley for providing mAb 29.7.

\section{References}

1. Santarelli JG, Sarkissian V, Hou LC, Veeravagu A, Tse V: Molecular events of brain metastasis. Neurosurg Focus 2007, 22:E1

2. Al-Shamy G, Sawaya R: Management of brain metastases: the indispensable role of surgery. J Neurooncol 2009, 92:275-282

3. Albini A, Sporn MB: The tumour microenvironment as a target for chemoprevention. Nat Rev Cancer 2007, 7:139-147

4. Joyce JA, Pollard JW: Microenvironmental regulation of metastasis. Nat Rev Cancer 2009, 9:239-252

5. Witkiewicz AK, Casimiro MC, Dasgupta A, Mercier I, Wang C, Bonuccell G, Jasmin JF, Frank PG, Pestell RG, Kleer CG, Sotgia F, Lisanti MP: Towards a new "stromal-based" classification system for human breast cancer prognosis and therapy. Cell Cycle 2009, 8:1654-1658

6. Nicolson GL, Menter DG, Herrmann JL, Yun Z, Cavanaugh P, Marchetti D: Brain metastasis: role of trophic, autocrine, and paracrine factors in tumor invasion and colonization of the central nervous system. Curr Top Microbiol Immunol 1996, 213(Pt 2):89-115

7. Zhang C, Zhang F, Tsan R, Fidler IJ: Transforming growth factor- $\beta 2$ is a molecular determinant for site-specific melanoma metastasis in the brain. Cancer Res 2009, 69:828-835

8. Calabrese C, Poppleton H, Kocak M, Hogg TL, Fuller C, Hamner B Oh EY, Gaber MW, Finklestein D, Allen M, Frank A, Bayazitov IT, Zakharenko SS, Gajjar A, Davidoff A, Gilbertson RJ: A perivascular niche for brain tumor stem cells. Cancer Cell 2007, 11:69-82

9. Carbonell WS, Ansorge O, Sibson N, Muschel R: The vascular basement membrane as "soil" in brain metastasis. PLoS One 2009, 4:e5857

10. Veeravagu A, Bababeygy SR, Kalani MY, Hou LC, Tse V: The cancer stem cell-vascular niche complex in brain tumor formation. Stem Cells Dev 2008, 17:859-867

11. Ballinger WE Jr, Schimpff RD: An experimental model for cerebral metastasis: preliminary light and ultrastructural studies. J Neuropathol Exp Neurol 1979, 38:19-34

12. Kawaguchi T, Tobai S, Nakamura K: Extravascular migration of tumor 
cells in the brain: an electron microscopic study. Invasion Metastasis 1982, 2:40-50

13. Paku S, Dome B, Toth R, Timar J: Organ-specificity of the extravasation process: an ultrastructural study. Clin Exp Metastasis 2000, 18:481-492

14. Daginakatte GC, Gutmann DH: Neurofibromatosis-1 (Nf1) heterozygous brain microglia elaborate paracrine factors that promote Nf1deficient astrocyte and glioma growth. Hum Mol Genet 2007, 16:1098-1112

15. Fitzgerald DP, Palmieri D, Hua E, Hargrave E, Herring JM, Qian Y, Vega-Valle E, Weil RJ, Stark AM, Vortmeyer AO, Steeg PS: Reactive glia are recruited by highly proliferative brain metastases of breast cancer and promote tumor cell colonization. Clin Exp Metastasis 2008, 25:799-810

16. He BP, Wang JJ, Zhang X, Wu Y, Wang M, Bay BH, Chang AY: Differential reactions of microglia to brain metastasis of lung cancer. Mol Med 2006, 12:161-170

17. Hoelzinger DB, Demuth T, Berens ME: Autocrine factors that sustain glioma invasion and paracrine biology in the brain microenvironment. J Natl Cancer Inst 2007, 99:1583-1593

18. Roggendorf W, Strupp S, Paulus W: Distribution and characterization of microglia/macrophages in human brain tumors. Acta Neuropathol 1996, 92:288-293

19. Markovic DS, Glass R, Synowitz M, Rooijen N, Kettenmann H: Microglia stimulate the invasiveness of glioma cells by increasing the activity of metalloprotease-2. J Neuropathol Exp Neurol 2005, 64:754-762

20. Markovic DS, Vinnakota K, Chirasani S, Synowitz M, Raguet H, Stock K, Sliwa M, Lehmann S, Kalin R, van Rooijen N, Holmbeck K, Heppner FL, Kiwit J, Matyash V, Lehnardt S, Kaminska B, Glass R, Kettenmann $\mathrm{H}$ : Gliomas induce and exploit microglial MT1-MMP expression for tumor expansion. Proc Natl Acad Sci USA 2009, 106:12530-12535

21. Murata J, Ricciardi-Castagnoli P, Dessous L'Eglise Mange P, Martin F, Juillerat-Jeanneret L: Microglial cells induce cytotoxic effects toward colon carcinoma cells: measurement of tumor cytotoxicity with a gamma-glutamyl transpeptidase assay. Int J Cancer 1997, 70:169-174

22. Zhang M, Olsson Y: Hematogenous metastases of the human braincharacteristics of peritumoral brain changes: a review. J Neurooncol 1997, 35:81-89

23. Marchetti D, Aucoin R, Blust J, Murry B, Greiter-Wilke A: p75 neurotrophin receptor functions as a survival receptor in brain-metastatic melanoma cells. J Cell Biochem 2004, 91:206-215

24. Marchetti D, Li J, Shen R: Astrocytes contribute to the brain-metastatic specificity of melanoma cells by producing heparanase. Cancer Res 2000, 60:4767-4770

25. Sierra A, Price JE, Garcia-Ramirez M, Mendez O, Lopez L, Fabra A: Astrocyte-derived cytokines contribute to the metastatic brain specificity of breast cancer cells. Lab Invest 1997, 77:357-368

26. Langley RR, Fan D, Guo L, Zhang C, Lin Q, Brantley EC, McCarty JH, Fidler IJ: Generation of an immortalized astrocyte cell line from $\mathrm{H}-2 \mathrm{~Kb}$-tsA58 mice to study the role of astrocytes in brain metastasis. Int J Oncol 2009, 35:665-672

27. JuanYin J, Tracy K, Zhang L, Munasinghe J, Shapiro E, Koretsky A, Kelly K: Noninvasive imaging of the functional effects of anti-VEGF therapy on tumor cell extravasation and regional blood volume in an experimental brain metastasis model. Clin Exp Metastasis 2009, 26:403-414

28. Yoneda T, Williams PJ, Hiraga T, Niewolna M, Nishimura R: A boneseeking clone exhibits different biological properties from the MDAMB-231 parental human breast cancer cells and a brain-seeking clone in vivo and in vitro. J Bone Miner Res 2001, 16:1486-1495

29. Lorger M, Krueger JS, O'Neal M, Staflin K, Felding-Habermann B: Activation of tumor cell integrin $\alpha_{\mathrm{v}} \beta_{3}$ controls angiogenesis and metastatic growth in the brain. Proc Natl Acad Sci USA 2009, 106: 10666-10671

30. Deryugina El, Quigley JP: Chick embryo chorioallantoic membrane model systems to study and visualize human tumor cell metastasis. Histochem Cell Biol 2008, 130:1119-1130

31. Lu W, Bucana CD, Schroit AJ: Pathogenesis and vascular integrity of breast cancer brain metastasis. Int J Cancer 2007, 120:1023-1026

32. Chambers AF: MDA-MB-435 and M14 cell lines: identical but not M14 melanoma? Cancer Res 2009, 69:5292-5293

33. Hollestelle A, Schutte M: Comment Re: MDA-MB-435 and M14 cell lines: identical but not M14 melanoma? Cancer Res 2009, 69:7893

34. Du R, Lu KV, Petritsch C, Liu P, Ganss R, Passegue E, Song H,
Vandenberg S, Johnson RS, Werb Z, Bergers G: HIF1 $\alpha$ induces the recruitment of bone marrow-derived vascular modulatory cells to regulate tumor angiogenesis and invasion. Cancer Cell 2008, 13:206-220

35. Fidler IJ, Schackert G, Zhang RD, Radinsky R, Fujimaki T: The biology of melanoma brain metastasis. Cancer Metastasis Rev 1999, 18:387-400

36. Puduvalli VK: Brain metastases: biology and the role of the brain microenvironment. Curr Oncol Rep 2001, 3:467-475

37. Davis EJ, Foster TD, Thomas WE: Cellular forms and functions of brain microglia. Brain Res Bull 1994, 34:73-78

38. Hayashi Y, Nomura M, Yamagishi S, Harada S, Yamashita J Yamamoto $\mathrm{H}$ : Induction of various blood-brain barrier properties in non-neural endothelial cells by close apposition to co-cultured astrocytes. Glia 1997, 19:13-26

39. Hurwitz AA, Berman JW, Rashbaum WK, Lyman WD: Human feta astrocytes induce the expression of blood-brain barrier specific proteins by autologous endothelial cells. Brain Res 1993, 625:238-243

40. Megard I, Garrigues A, Orlowski S, Jorajuria S, Clayette P, Ezan E, Mabondzo A: A co-culture-based model of human blood-brain barrier: application to active transport of indinavir and in vivo-in vitro correlation. Brain Res 2002, 927:153-167

41. Tamagno I, Schiffer D: Nestin expression in reactive astrocytes of human pathology. J Neurooncol 2006, 80:227-233

42. Hobilkova A, Ehrmann J, Knizetova P, Krejci V, Kalita O, Kolar Z: Analysis of VEGF, Flt-1, Flk-1, nestin and MMP-9 in relation to astrocytoma pathogenesis and progression. Neoplasma 2009, 56:284-290

43. Wang HH, Hsieh HL, Wu CY, Yang CM: Oxidized low-density lipoprotein-induced matrix metalloproteinase-9 expression via PKC- $\delta / p 42 / p 44$ MAPK/Elk-1 cascade in brain astrocytes. Neurotox Res 2010, 17:50-65

44. Bonavia R, Bajetto A, Barbero S, Pirani P, Florio T, Schettini G: Chemokines and their receptors in the CNS: expression of CXCL12/ SDF-1 and CXCR4 and their role in astrocyte proliferation. Toxicol Lett 2003, 139:181-189

45. Cui X, Chen J, Zacharek A, Li Y, Roberts C, Kapke A, SavantBhonsale S, Chopp M: Nitric oxide donor upregulation of stromal cell-derived factor-1/chemokine (CXC motif) receptor 4 enhances bone marrow stromal cell migration into ischemic brain after stroke. Stem Cells 2007, 25:2777-2785

46. Peng H, Erdmann N, Whitney N, Dou H, Gorantla S, Gendelman HE, Ghorpade A, Zheng J: HIV-1-infected and/or immune activated macrophages regulate astrocyte SDF-1 production through IL-1 $\beta$. Glia 2006, 54:619-629

47. Xu Q, Wang S, Jiang X, Zhao Y, Gao M, Zhang Y, Wang X, Tano K, Kanehara M, Zhang W, Ishida T: Hypoxia-induced astrocytes promote the migration of neural progenitor cells via vascular endothelial factor, stem cell factor, stromal-derived factor- $1 \alpha$ and monocyte chemoattractant protein-1 upregulation in vitro. Clin Exp Pharmacol Physiol 2007, 34:624-631

48. Nieswandt B, Hafner M, Echtenacher B, Mannel DN: Lysis of tumor cells by natural killer cells in mice is impeded by platelets. Cancer Res 1999, 59:1295-1300

49. Bos PD, Zhang XH, Nadal C, Shu W, Gomis RR, Nguyen DX, Minn AJ, van de Vijver MJ, Gerald WL, Foekens JA, Massague J: Genes that mediate breast cancer metastasis to the brain. Nature 2009, 459:1005-1009

50. Al-Mehdi AB, Tozawa K, Fisher AB, Shientag L, Lee A, Muschel RJ: Intravascular origin of metastasis from the proliferation of endothelium-attached tumor cells: a new model for metastasis. Nat Med 2000 6:100-102

51. Chambers AF, MacDonald IC, Schmidt EE, Koop S, Morris VL, Khokha R, Groom AC: Steps in tumor metastasis: new concepts from intravital videomicroscopy. Cancer Metastasis Rev 1995, 14:279-301

52. Chambers AF, MacDonald IC, Schmidt EE, Morris VL, Groom AC Clinical targets for anti-metastasis therapy. Adv Cancer Res 2000, 79:91-121

53. Chambers AF, Schmidt EE, MacDonald IC, Morris VL, Groom AC: Early steps in hematogenous metastasis of B16F1 melanoma cells in chick embryos studied by high-resolution intravital videomicroscopy. J Natl Cancer Inst 1992, 84:797-803

54. Kosir MA, Wang W, Zukowski KL, Tromp G, Barber J: Degradation of basement membrane by prostate tumor heparanase. J Surg Res 1999, 81:42-47

55. Kawaguchi T, Kawaguchi M, Miner KM, Lembo TM, Nicolson GL: 
Brain meninges tumor formation by in vivo-selected metastatic B16 melanoma variants in mice. Clin Exp Metastasis 1983, 1:247-259

56. Bachelder RE, Crago A, Chung J, Wendt MA, Shaw LM, Robinson G, Mercurio AM: Vascular endothelial growth factor is an autocrine survival factor for neuropilin-expressing breast carcinoma cells. Cancer Res 2001, 61:5736-5740

57. Buffo A, Rite I, Tripathi P, Lepier A, Colak D, Horn AP, Mori T, Gotz M: Origin and progeny of reactive gliosis: a source of multipotent cells in the injured brain. Proc Natl Acad Sci USA 2008, 105:3581-3586

58. Itoh T, Satou T, Hashimoto S, Ito H: Isolation of neural stem cells from damaged rat cerebral cortex after traumatic brain injury. Neuroreport 2005, 16:1687-1691

59. Sofroniew MV: Reactive astrocytes in neural repair and protection. Neuroscientist 2005, 11:400-407

60. Alvarez-Buylla A, Herrera DG, Wichterle H: The subventricular zone: source of neuronal precursors for brain repair. Prog Brain Res 2000, 127:1-11

61. Faiz M, Acarin L, Villapol S, Schulz S, Castellano B, Gonzalez B: Substantial migration of SVZ cells to the cortex results in the generation of new neurons in the excitotoxically damaged immature rat brain. Mol Cell Neurosci 2008, 38:170-182

62. Ghashghaei HT, Weimer JM, Schmid RS, Yokota Y, McCarthy KD, Popko B, Anton ES: Reinduction of ErbB2 in astrocytes promotes radial glial progenitor identity in adult cerebral cortex. Genes Dev 2007, 21:3258-3271
63. Heyn C, Ronald JA, Ramadan SS, Snir JA, Barry AM, MacKenzie LT, Mikulis DJ, Palmieri D, Bronder JL, Steeg PS, Yoneda T, MacDonald IC, Chambers AF, Rutt BK, Foster PJ: In vivo MRI of cancer cell fate at the single-cell level in a mouse model of breast cancer metastasis to the brain. Magn Reson Med 2006, 56:1001-1010

64. Luzzi KJ, MacDonald IC, Schmidt EE, Kerkvliet N, Morris VL, Chambers AF, Groom AC: Multistep nature of metastatic inefficiency: dormancy of solitary cells after successful extravasation and limited survival of early micrometastases. Am J Pathol 1998, 153:865-873

65. Bachoo RM, Kim RS, Ligon KL, Maher EA, Brennan C, Billings N Chan S, Li C, Rowitch DH, Wong WH, DePinho RA: Molecular diversity of astrocytes with implications for neurological disorders. Proc Natl Acad Sci USA 2004, 101:8384-8389

66. Wilkin GP, Marriott DR, Cholewinski AJ: Astrocyte heterogeneity. Trends Neurosci 1990, 13:43-46

67. Mori T, Buffo A, Gotz M: The novel roles of glial cells revisited: the contribution of radial glia and astrocytes to neurogenesis. Curr Top Dev Biol 2005, 69:67-99

68. Chmielnicki E, Benraiss A, Economides AN, Goldman SA: Adenovirally expressed noggin and brain-derived neurotrophic factor cooperate to induce new medium spiny neurons from resident progenitor cells in the adult striatal ventricular zone. J Neurosci 2004 24:2133-2142 